THE ANNALS OF "DUNĂREA DE JOS" UNIVERSITY OF GALATI

FASCICLE III, 2020, VOL. 43, SPECIAL ISSUE, ISSN 2344-4738, ISSN-L 1221-454X

ELECTROTECHNICS, ELECTRONICS, AUTOMATIC CONTROL, INFORMATICS

Article DOI: https://doi.org/10.35219/eeaci.2020.2.04

\title{
CONTROL OF A BLDC MOTOR IN REAL TIME - EDUCATIONAL STAND
}

\author{
Claudia Mihaela Nicolau \\ Department of Automation and Electrical Engineering, "Dunărea de Jos" University \\ of Galați, România \\ e-mail:nicolau.claudia97@gmail.com
}

\begin{abstract}
This paper presents the control process of a brushless motor using an electronic speed controller and an incremental encoder. The brushless motor speed control and monitoring are implemented in real time using an Arduino Mega2560 microcontroller and a W5100 Ethernet communication module. The purpose of this paper is to create an educational stand necessary to control the BLDC (Brushless Direct Current) motor in open and closed loop. The reason for approaching this current topic is due to the widespread use of this motor and its complexity. Because the control of a BLDC is realized by electronic switching, it is necessary to know the switching intervals of its windings.
\end{abstract}

Keywords: BLDC motor, PWM, back electromotive force, PID.

\section{INTRODUCTION}

The coil rotor asynchronous motors and DC motors have limitations such as rated speed, electromagnetic interference problems, low efficiency, low starting torque and wear of the brushes-collector assembly (Nicolau, 2019). Because of this fact, brushless synchronous motors and mechanical switches have been developed. Commutation of the windings it is realized using the command inverter, which feeds the motor phases according to the position of the rotor. BLDC motors usually presents a six-step switch and Hall-effect sensors are frequently used to determine the position of the rotor relative to the stator, the method being agreed due to its accuracy (Mohammed, 2014) and (Cham, 2014). The cost is high during both the manufacture and exploitation, but especially it has operating constraints under certain environmental conditions (heat and high humidity). For these reasons, in this paper we did not choose to do the control with Hall effect sensors, but we choosed an incremental position sensor. BLDC motors are increasingly used in applications such as (https://www.kdedirect.com/blogs/news/6-industryapplications-brushless-motors):

- Aerospace and defense: Major players such as NASA (National Aeronautics and Space
Administration) use these types of motors for Apollo ship support blowers, which make it possible for oxygen to circulate inside turbines.

- Marin: The submarine drones used by marine researchers and underwater cartographers have in their structure a BLDC motor with an IP 66 degree of protection, which allows the exploration of waters at greater depths than divers can reach, underwater vehicles with propulsion, winches.

- Medical: Their use in the medical industry registered in 2018 a significant increase. Brushless motors are used because there are environments where sparks could be dangerous or could adversely affect electronically sensitive medical equipment. Due to the silent operation, sleep apnea equipment is equipped with such motors and must meet the noise standards.

- Robotics: In addition to low noise during operation, BLDC motors manage more peak current and higher speeds, making them ideal for the epoch of automation; service robots, prosthetic limbs and BattleBots.

The special interest for these type of actions is due to the outstanding performances that characterize BLDC motors: higher speeds of tens of thousands, 
THE ANNALS OF "DUNĂREA DE JOS" UNIVERSITY OF GALATI

FASCICLE III, 2020, VOL. 43, SPECIAL ISSUE, ISSN 2344-4738, ISSN-L 1221-454X

ELECTROTECHNICS, ELECTRONICS, AUTOMATIC CONTROL, INFORMATICS

Article DOI: $\underline{\text { https://doi.org/10.35219/eeaci.2020.2.04 }}$

high torque/overall ratio, high efficiency and reliability, low maintenance, elimination of ionized sparks from the collector and general reduction of electromagnetic interference (https://biblioteca.regielive.ro/licente/electrotehnica/s tudiul-unui-motor-bldc-272146.html).

\subsection{Construction of a motor with electronic commutation}

A conventional DC motor consists of an inner coil rotor and an outer stator with magnets. The transfer of current to and from the rotor is done by brushes that are fixed on the stator which presses on the rotor, this being the weak point of DC motors (https://biblioteca.regielive.ro/licente/electrotehnica/s tudiul-unui-motor-bldc-272146.html). Due to the physical contact between the components, wear occurs faster and consequently the efficiency of the motor is affected. A brushless DC motor is constructively similar to a conventional DC motor with an inverted construction (https://biblioteca.regielive.ro/licente/electrotehnica/s tudiul-unui-motor-bldc-272146.html). This means that the coils are on the outside and the permanent magnets on the inside. What is sought is the absence of physical contact between the stator and the rotor. The stator consists of several coils through which current flows, which create a rotating magnetic field. Three phases are required to obtain six different paths for the current to flow. The controller is responsible for redirecting the current to quickly change the magnetic field. The controller must have information on the position of the rotor, and this information is transmitted to it by the position sensors or more modernly by detecting the level of electromotive force self-induced in the stator windings by permanent magnets. The stator (Fig. 1) of an electronically switch motor has in its construction stacked steel sheets in which the windings are placed. There are two types of windings, trapezoidal and sinusoidal. This difference is given by the interconnection of the coils in the stator windings to result in different types of opposed electromotive force.

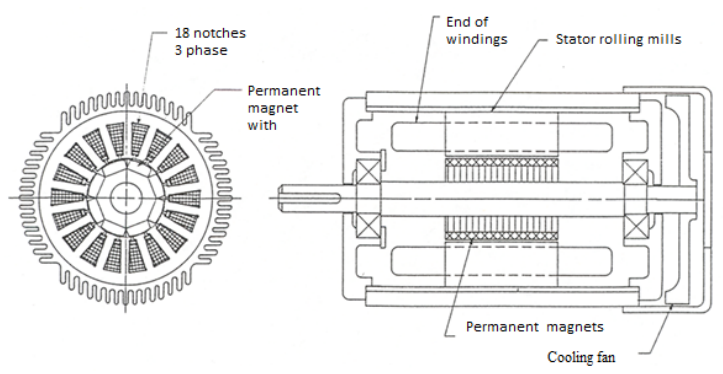

Fig. 1. Stator and longitudinal section of a BLDC motor (https://biblioteca.regielive.ro/licente/electrotehnica/s tudiul-unui-motor-bldc-272146.html)

Trapezoidal-winded asynchronous motors develop a rectangular (trapezoidal) waveform of back-EMF (electromotive force), while brushless DC motors with a sinusoidal winding have a sinusoidal backEMF. In addition to the opposed electromotive force, the phase current also has trapezoidal and sinusoidal variations in these types of motors. This makes the torque variation on a sinusoidal motor smoother than of a trapezoidal motor.

\subsection{The structure of a brushless motor drive system}

Fig. 2 shows the block diagram of a control and command system for a three-phase brushless motor using the star connection. In the diagram, the blocks are marked from $\mathrm{A}$ to $\mathrm{D}$ and they represent the composition of the electronic speed controller. In practice, according to the new design concepts, the delimitation line between certain blocks may no longer appear, the functions of one group of circuits can be found in the other group (Mic, 2007).

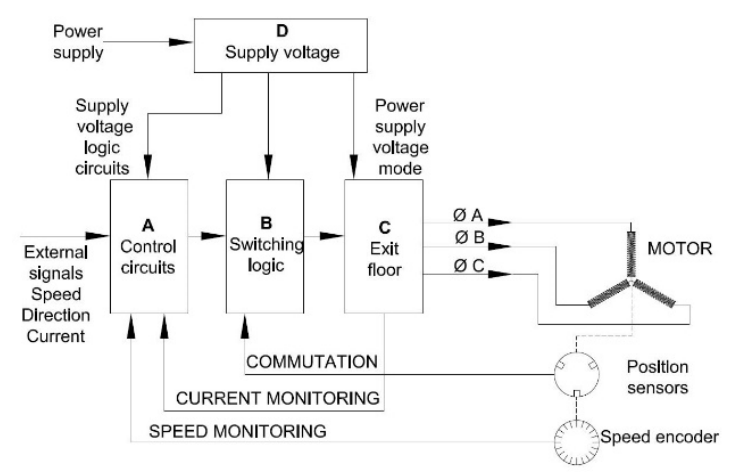

Fig. 2. Elements of a drive system for a brushless motor (Mic, 2007)

\subsection{Electronic phases switching of the motor}

Each phase contains a motor end in the "high" state, a motor end in the "low" state and another end in the "float state" which define the six rotor positions. The currents are switched so that the rotor moves to the next position, which causes the rotor to rotate. Each rotor position has an associated winding configuration.

By successively changing the winding configuration, forward or backward rotations can be obtained depending on the order of the phase sequence. The control of the currents on the windings is done with the help of power switching transistors, each winding having its own transient. These are usually MOSFETs (Metal Oxide Semiconductor Field Effect Transistors) controlled in time-modulated pulses in 
THE ANNALS OF "DUNĂREA DE JOS" UNIVERSITY OF GALATI

FASCICLE III, 2020, VOL. 43, SPECIAL ISSUE, ISSN 2344-4738, ISSN-L 1221-454X

ELECTROTECHNICS, ELECTRONICS, AUTOMATIC CONTROL, INFORMATICS

Article DOI: https://doi.org/10.35219/eeaci.2020.2.04

order to adjust the tension on the windings. The scheme of switching the motor phases is shown in Fig. 3 (Kumar, 2014).

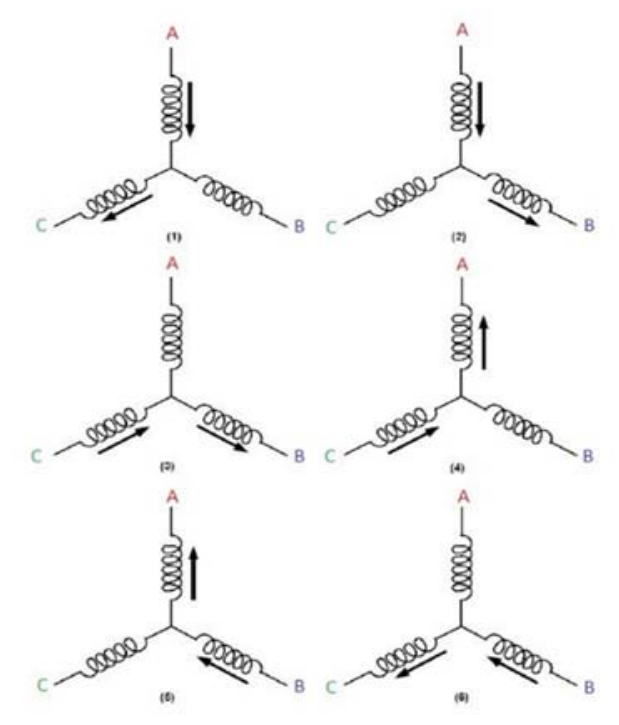

Fig. 3.The six switching sequences of the motor windings

\subsection{PWM Control}

The method that will be used to control the voltage and implicitly the speed, that is the most used for BLDC motors, is the duration modulation of the pulses. The following is the relationship between the inverter supply voltage and the voltage applied to the brushless motor stator (http://www.teslainstitute.com/!download/files/ARDUINO Functions_Reference_-_TESLA_INSTITUTE.pdf):

$$
\begin{aligned}
& \text { (1) } \mathrm{U}_{\text {med }}=\mathrm{d} \cdot \mathrm{U}_{\mathrm{dc}} \\
& \text { (2) } d=\frac{T_{\text {on }}}{T_{\text {on }}+T_{\text {off }}}=\frac{T_{\text {on }}}{T} \\
& \text { (3) } \mathrm{d}[\%]=\mathrm{d} \cdot 100
\end{aligned}
$$

The PWM signal generation mode, most often used to control BLDC motors is according to the setpoints, being the standard or "edge-aligned" mode. When choosing the frequency of the PWM (Pulse Width Modulation) signal, several aspects need to be considered. The higher the PWM signal frequency, the higher the transistor switching losses. If a too low PWM signal frequency is applied, it will have an effect on the current in the stator windings whose profile will be composed of a series of high value pulses, followed by intervals in which the current value is zero, it can achieve a jerky motor rotation and also an intermittent couple. The ideal frequency depends on the characteristics of the motor, especially the value of the induction of the stator windings. A convenient value of the PWM signal frequency is found in the range $10-20 \mathrm{KHz}$. This also adapts to the value of the available input frequency (Mic, 2007).Arduino Mega generates PWM signal on digital ports from pin 2 (inclusive) to pin 13 and from pin 44 to pin 46 (http://www.teslainstitute.com/!download/files/ARDUINO Functions Reference - TESLA_INSTITUTE.pdf).

Fig. 4 shows the components of the PWM signal.

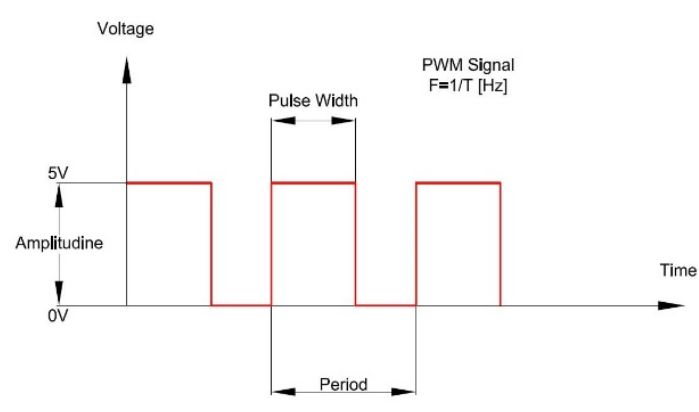

Fig. 3. PWM signal components

\subsection{Six step trapezoidal commutation}

The method of feeding the motor windings in the sensor-free algorithm involves trapezoidal switching in six steps or $120^{\circ}$ electric. To start the BLDC motor, the stator windings must be fed in the correct order, the sequences being determined based on the rotor positioning signals (Torres, 2008). For the control of the motor windings, the method of the six trapezoidal steps shown in the Fig. 5.

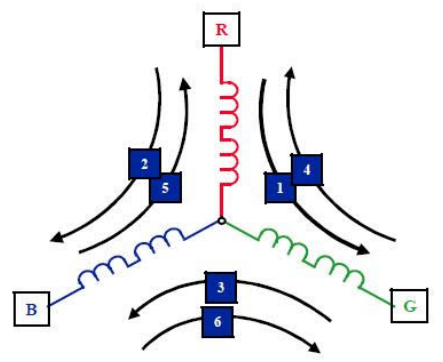

Fig. 4. The sequence of the six switching steps (Torres, 2008)

The arrows in the diagram indicate the direction of the current through the motor windings for each of the six switching steps. The graph below illustrates the voltage applied to each of the motor endings during the six switching steps. Going through these switching steps causes a complete rotation of the rotor. 
THE ANNALS OF "DUNĂREA DE JOS" UNIVERSITY OF GALATI

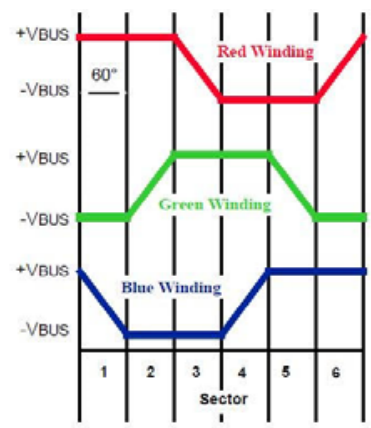

Fig. 5. BLDC Motor windings and trapezoidal waveforms (Torres, 2008)

Table 1: Switching sequence

\begin{tabular}{|c|c|c|c|c|}
\hline $\begin{array}{c}\text { Switching } \\
\text { interval }\end{array}$ & $\begin{array}{c}\text { Sequence } \\
\text { number }\end{array}$ & \multicolumn{2}{|c|}{ Phase A } & \multicolumn{2}{|c|}{ Phase B } & Phase C \\
\hline $\mathbf{0}^{\circ}-\mathbf{6 0}^{\circ}$ & 0 & + & - & disconnect \\
\hline $\mathbf{6 0}^{\circ}-\mathbf{1 2 0 ^ { \circ }}$ & 1 & + & disconnect & - \\
\hline $\mathbf{1 2 0}^{\circ}-\mathbf{1 8 0}^{\circ}$ & 2 & disconnect & + & - \\
\hline $\mathbf{1 8 0}^{\circ}-\mathbf{2 4 0 ^ { \circ }}$ & 3 & - & + & disconnect \\
\hline $\mathbf{2 4 0}^{\circ}-\mathbf{3 0 0}^{\circ}$ & 4 & - & disconnect & + \\
\hline $\mathbf{3 0 0}^{\circ}-\mathbf{3 6 0 ^ { \circ }}$ & 5 & disconnect & - & + \\
\hline & & & & + \\
\hline
\end{tabular}

A switching sequence consists of the three windings that are based on the principle presented above. The

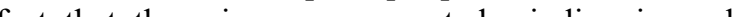
switching sequence is an important feature of the sixstep control that allows the use of a sensor-free control algorithm.

\section{STRUCTURE HARWARE AND SOFTWARE}

This section describes the hardware components used to create the educational stand and the software developed to be able to monitor the response of the system based on the required setpoint, the parameters of the controller and the encoder.

\subsection{Mechanical structure}

Fig. 7 illustrates the practical implementation of the stand. All components were placed on a board made by a 3D printer, which is provided with supports for the gear motor and encoder assembly.

The components of the structure are the following:

- Support plate;

- Potentiometer;

- Brushless motor;

- Reduction;

- Coupling;

- Encoder.

An inevitable disadvantage is the decrease of the efficiency of this assembly, due to the internal frictions in the reducer bearings, which lead to the impossibility of finding an exact mathematical model that also characterizes the system.

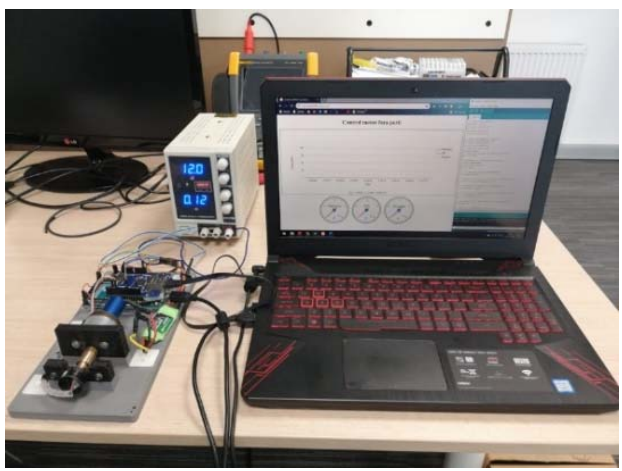

Fig. 7. Control system

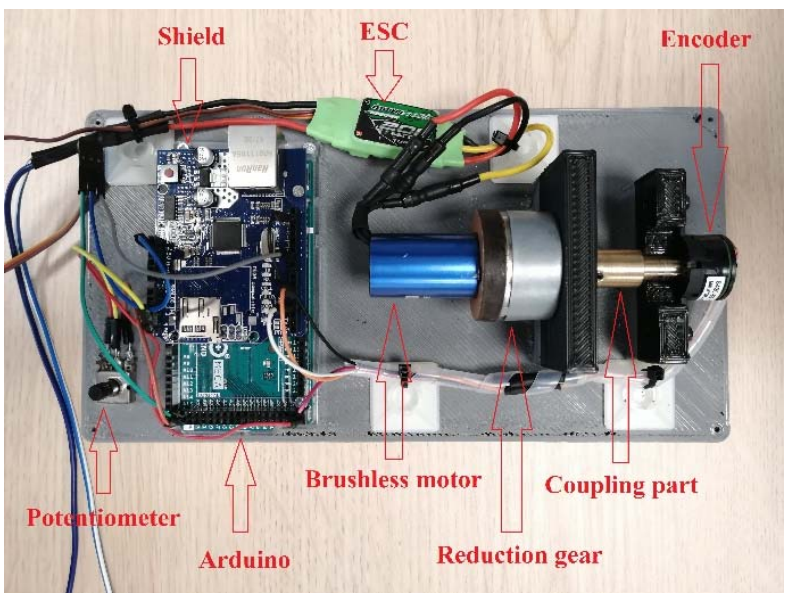

Fig. 8. Educational stand

A speed setpoint is applied at the system input and Arduino calculates the values that are transmitted to the ESC. The controller transmits the ESC command to control the voltage applied to the motor ends and the encoder transmits the feedback to the Arduino. The data retrieved from Arduino is stored in MySQL, and finally uploaded to the web interface. All these explanations are associated with the block diagram of the system shown in Fig. 9. 
THE ANNALS OF "DUNĂREA DE JOS" UNIVERSITY OF GALATI

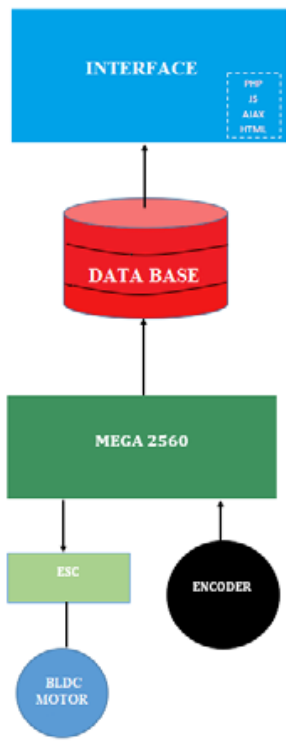

Fig. 9. System block diagram

\section{BLDC MOTOR CONTROL AND MONITORING}

\subsection{Open loop control}

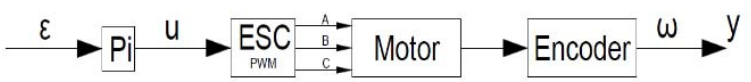

Fig. 10. Diagram of the open loop adjustment system

Switching without physical sensors requires a minimum speed for the motor to run. This is due to the fact that the amplitude of the back-electromotive voltage is proportional to the angular velocity of the rotor. Below the speed limit, the signal-to-noise ratio of the back-electromotive voltage over which the PWM signal overlaps is too small, so unsatisfactory. The lower speed limit depends on the PWM signal width, motor characteristics and supply voltage.

When the BLDC motor starts, it initially consumes a large current and accelerates rapidly until the backelectromotive voltage limits the speed above the set supply voltage. Current limitation must take place during start/acceleration on the slope. This is an extremely important aspect of brushless DC motors, as they behave like a short-circuit when the rotor does not rotate.

The current can be limited by the control in the openloop voltage by compensating the speed-dependent back-electromotive voltage or by the closed-loop control by taking the reaction signal from the encoder.
The characteristics of the PWM signal and the observation of the change of the filling factor based on the required setpoint are presented below. The filling factor is expressed as a percentage and represents what percentage of the signal period it will be on logic level 1 .

The PWM signal was acquired from the output of the digital port 13 of a Fluke 190-504 oscilloscope for the following setpoint values: $10 \%, 20 \%, 30 \%, 40 \%$. The amplitude of the PWM signal is between $+4.88 \mathrm{~V}$ and $+4.64 \mathrm{~V}$.

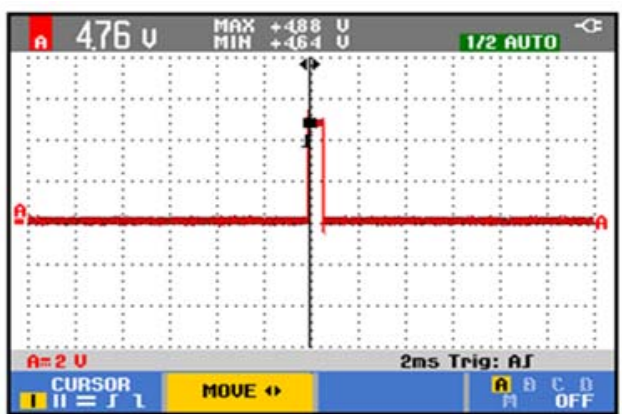

Fig. 11. PWM signal amplitude

Data displayed on the serial monitor and PWM signal period for the setpoints of $10 \%, 20 \%, 30 \%$ and $40 \%$ are presented in Figs 12 - 19:

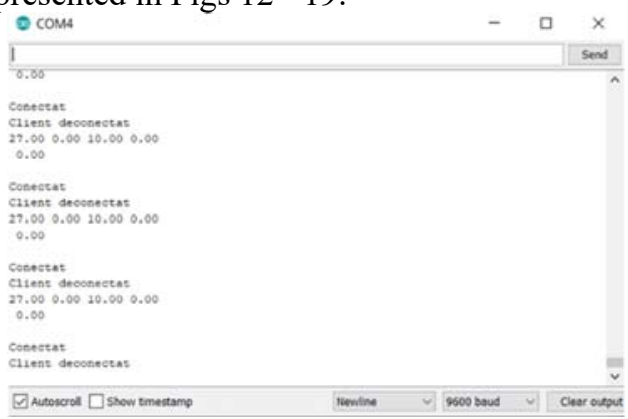

Fig. 12. Data displayed on the serial monitor for $10 \%$ setpoint

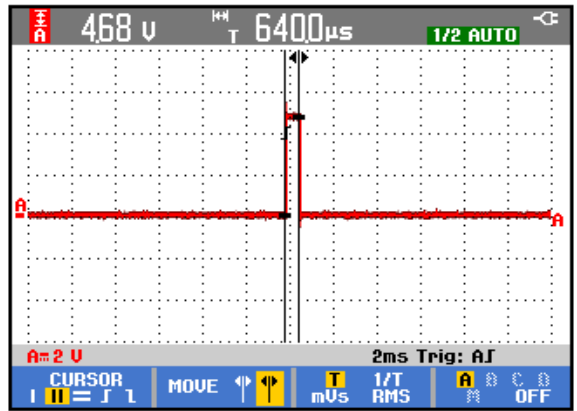

Fig. 13. PWM signal period for $10 \%$ setpoint 
THE ANNALS OF "DUNĂREA DE JOS" UNIVERSITY OF GALATI

FASCICLE III, 2020, VOL. 43, SPECIAL ISSUE, ISSN 2344-4738, ISSN-L 1221-454X

ELECTROTECHNICS, ELECTRONICS, AUTOMATIC CONTROL, INFORMATICS

Article DOI: https://doi.org/10.35219/eeaci.2020.2.04

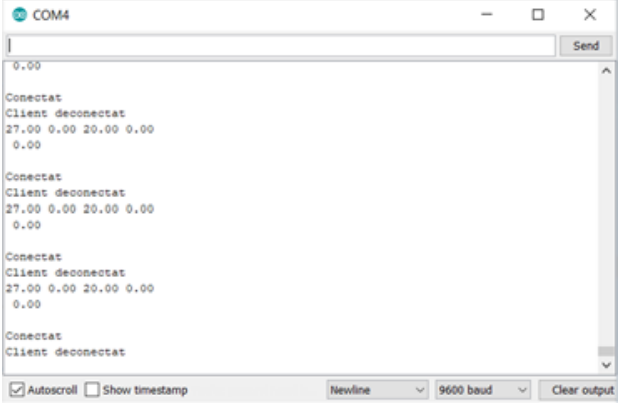

Fig. 14. Data displayed on the serial monitor for $20 \%$ setpoint

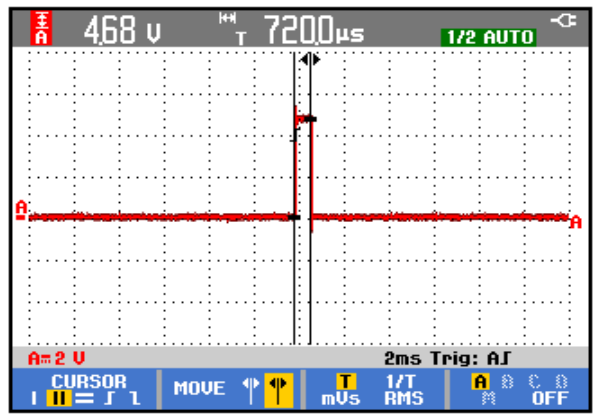

Fig. 15. PWM signal period for $20 \%$ setpoint

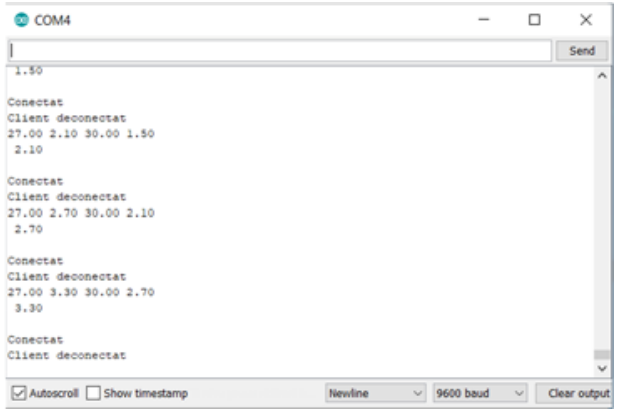

Fig. 16. Data displayed on the serial monitor for $30 \%$ setpoint

It was found that following the change of the setpoint, the pulse period changes. When the setpoint is set to $30 \%$ of maximum motor power, the resistive mounting torque is defeated, with the motor starting.

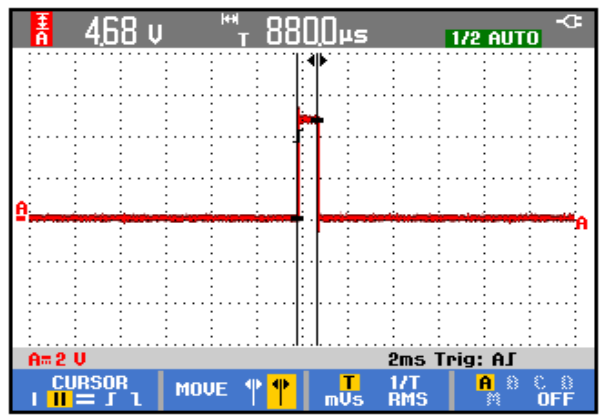

Fig. 17. PWM signal period for $30 \%$ setpoint

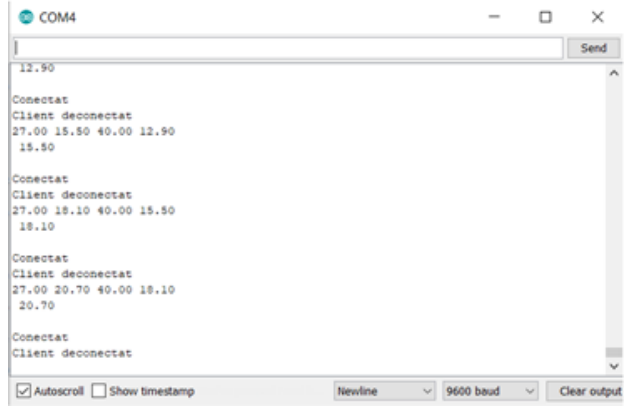

Fig. 18. Data displayed on the serial monitor for $40 \%$ setpoint

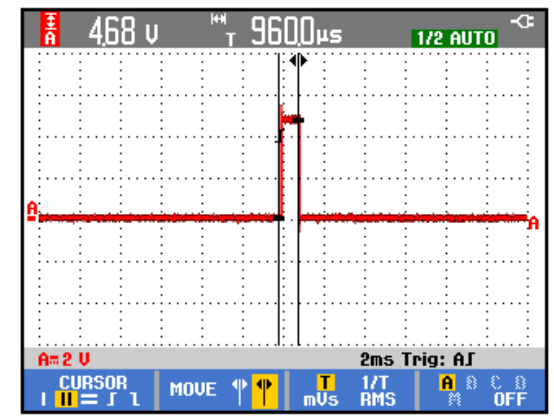

Fig. 19. PWM signal period for $40 \%$ setpoint

\subsection{Close loop control}

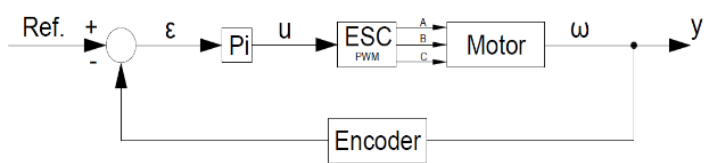

Fig. 20. Diagram of the closed loop adjustment system

The closed loop speed can be controlled by measuring motor speed. A PID (Proportional Integral Derivative) controller can be used to amplify the speed error and dynamically adjust the PWM signal period, but tunning the PID controller aims to determine the optimal values for the coefficients $\mathrm{Kp}$ and $\mathrm{Ki}$, the $\mathrm{Kd}$ component being set to 0 . In reality the behavior of the motor without brushes can be very well described by a first order process. That is the reason why a PI controller was used (the use of the derivative component would lead to an oscillating system, affecting the performance of the system).

The controller parameters have been declared and initialized in the Arduino IDE. 
THE ANNALS OF "DUNĂREA DE JOS" UNIVERSITY OF GALATI

FASCICLE III, 2020, VOL. 43, SPECIAL ISSUE, ISSN 2344-4738, ISSN-L 1221-454X

ELECTROTECHNICS, ELECTRONICS, AUTOMATIC CONTROL, INFORMATICS

Article DOI: https://doi.org/10.35219/eeaci.2020.2.04

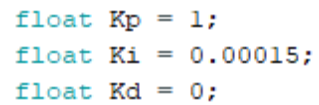

Fig. 21. Declaration and initialization of regulator parameters

For high-precision measurements, an incrementaltype optical encoder was used, which takes over the motor revolution through a 1:100 gearbox, the encoder giving two signals (A and B) with a phase difference of $90^{\circ}$. Using these signals, both speed and direction of rotation can be determined. This encoder also provides a third signal $(Z)$ that represents a pulse on a rotation (https://www.electronica-azi.ro/2005/ 12/20/encodere-incrementale-tip-seletsen/). It can be used for positioning applications, which in this case was not necessary. A setpoint is applied to the system input, the input controller receives the error signal which represents the difference between the required value and the current value. The controller transmits the control to the electronic speed controller, which in turn controls the voltage applied to the motor terminals. The feedback taken from the encoder is compared with the setpoint and the loop is resumed. In Fig. 22 it can be seen the voltage on the positive alternation $(+3.28 \mathrm{~V})$ and on the negative alternation $3.36 \mathrm{~V}$ measured at the motor terminals.

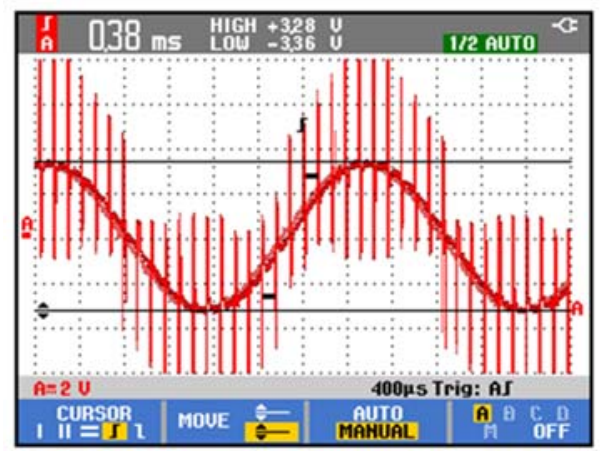

Fig. 22. Voltage measured at motor terminals

This time three setpoint values were chosen to measure the two-phase voltage at the motor terminals. The tests were performed for setpoint values of $30 \%, 35 \%$ and $40 \%$. These values were chosen because the motor starts from $30 \%$, the torque resistive to the motor shaft being high enough for the motor to start below this threshold.

\section{Setpoint - 30\%:}

Tunning the PI controller involves identifying the optimal values for the coefficients $\mathrm{Kp}$ and $\mathrm{Ki}$.

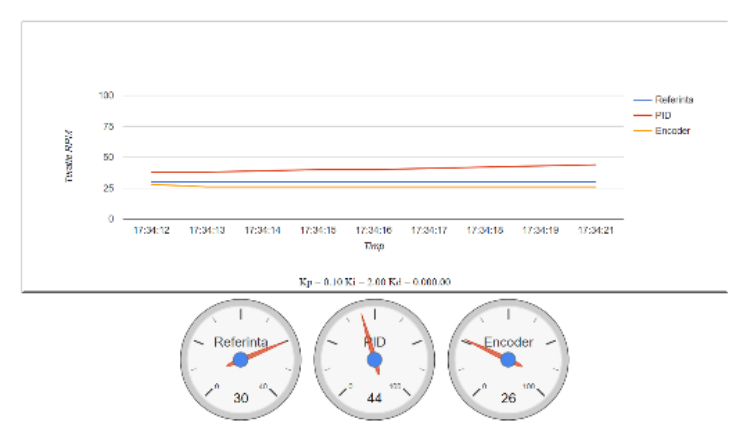

Fig. 23. Observation of the system response with a $30 \%$ setpoint

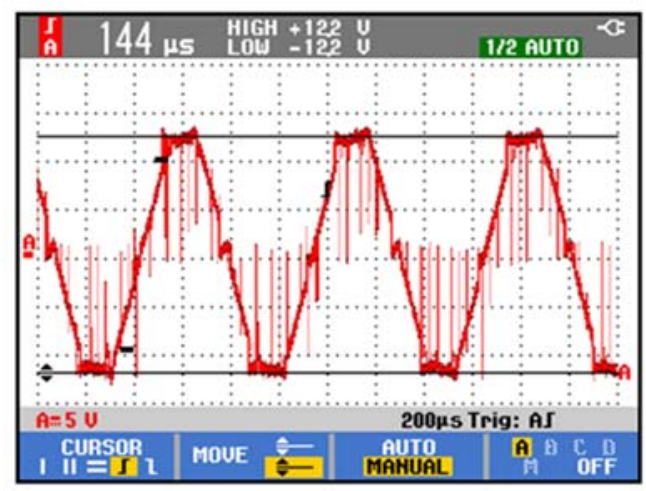

Fig. 24. Voltage measured at the motor terminals with a $30 \%$ setpoint

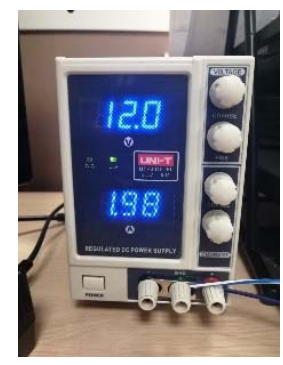

Fig. 25. Voltage and current value with a $30 \%$ setpoint

Setpoint - 35\%:

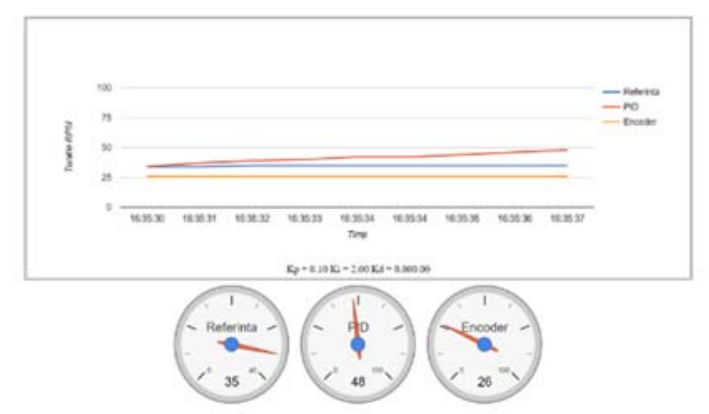


THE ANNALS OF "DUNĂREA DE JOS" UNIVERSITY OF GALATI

Fig. 26. Observation of the system response with a $35 \%$ setpoint

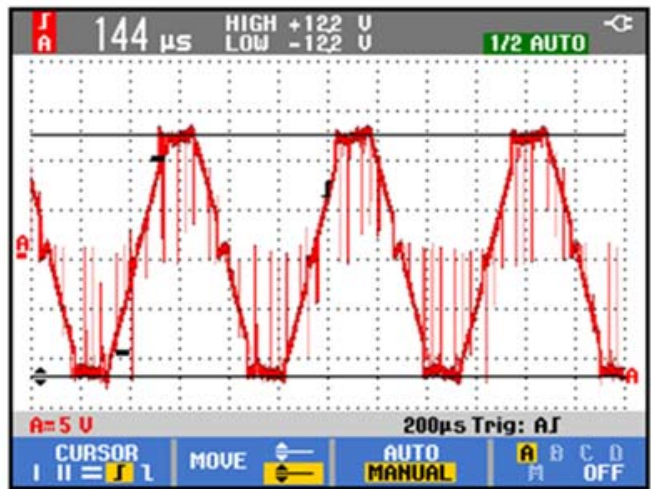

Fig. 27. Voltage measured at the motor terminals with a $35 \%$ setpoint

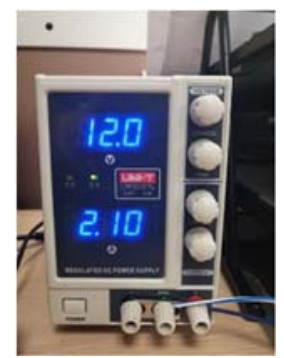

Fig. 28. Voltage and current value with a $35 \%$ setpoint

\section{$\underline{\text { Setpoint }-40 \%}$ :}

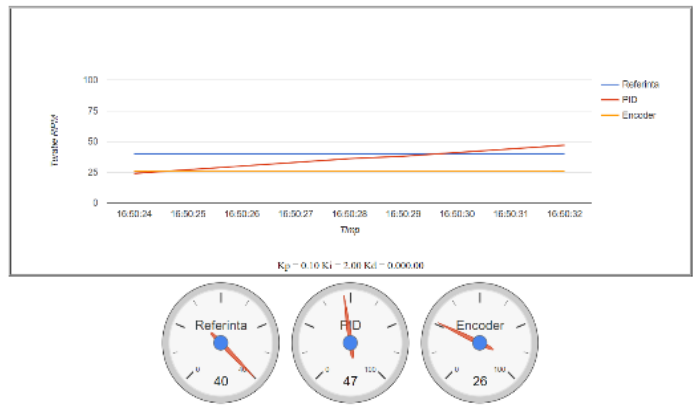

Fig. 29. Observation of the system response with a $40 \%$ setpoint

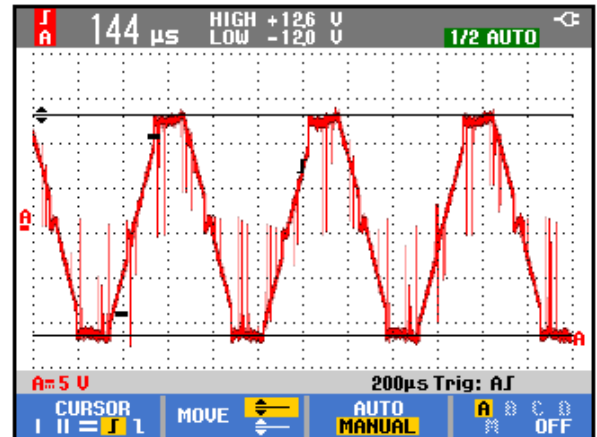

Fig. 30. Voltage measured at motor terminals with a $40 \%$ setpoint

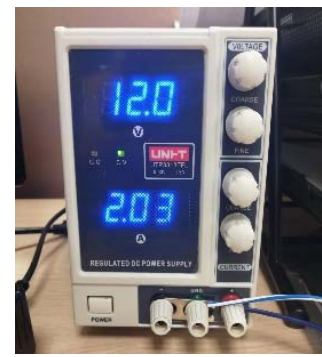

Fig. 31.Voltage and current value with a $40 \%$ setpoint

\section{CONCLUSION}

Following the tests, it was found that from the moment of starting, the motor accelerates until it exceeds the required setpoint, the controller minimizes the error and sends a control signal to the ESC (Electronic Speed Controller) to vary the motor speed. The feedback is transmitted by the encoder and the computing part is resumed. The noise that overlaps with the PWM signal is very high and produces significant losses in the system, which is not desired.

There were also limitations in adjusting the system, such as the calibration of the electronic speed controller, the lack of the motor data sheet in order to make an accurate determination of the motor performance and power losses due to friction in the gear of the three-speed gearbox.

Possible directions for the development of the paper:

- Integration in a consumer application which establishes the system performance;

- Development of a predictive regulator, so the parameters of the regulator will no longer be pure constants; 
THE ANNALS OF "DUNĂREA DE JOS" UNIVERSITY OF GALATI

- Establishing a connection via the Internet and its remote control;

- In the future, as an improvement, an automatic reading and calculation function of the controller parameters and an ESC calibration function can be implemented.

\section{REFERENCE}

Nicolau, C.; (2019), Controlul unui motor fara periiStand didactic, Bachelor thesis, FACIEE, "Dunărea de Jos" University, Galati, Romania.

Mohammed, I.; Santanu, M.; Syed, S. A.; Kruthi, J., B.E. 8th Sem EEE BNMIT, Bangalore,B.E. 8th Sem EEE BNMIT, Bangalore, B.E. 8th Sem EEE BNMIT, Bangalore,Assistant Professor BNMIT, Bangalore; (2014), Simulation and Analysis of Closed Loop Speed Control of Brushless DC Motor, International Journal of Advanced Information Science and Technology (IJAIST); ISSN: 2319:268 Vol.3, No.5, pp. 4053.

Cham, C. L. and Samad, Z. B.; (2014), Brushless DC Motor Electromagnetic Torque Estimation with Single-Phase Current Sensing", JEET; ISSN: 866-872 Vol.9, No.3, pp. 866-872.

Mic, D.; (2007), Contribuţii la dezvoltarea unui mediu integrat hardware-software pentru controlul motoarelor electrice cu circuite logice programabile, Doctoral thesis resume, IESC, "Transilvania" University, Brasov, Romania.

Kumar, N. Y.; Rao, E. P.; Varma, V. P.; Vikas, R. V. V. and Naidu, K. P.; (2014), Speed Control of Bldc Motor Drive By Using Pid Controllers, Int. Journal of Engineering Research and Applications, IJERA, ISSN : 2248-9622, Vol. 4, Issue 4( Version 4), pp. 37-41.

Torres, D.; (2008), Sensorless BLDC Control with Back-EMF Filtering Using A Majority Function, AN1106, Microchip Technology Inc., ISO/TS16949:2002, pp. 1-25. 